九州大学学術情報リポジトリ

Kyushu University Institutional Repository

\title{
Effective passivation of defects in Ge-rich SiGe-on-insulator substrates by Al_20_3 deposition and subsequent post-annealing
}

Yang, Haigui

Art, Science and Technology Center for Cooperative Research, Kyushu University

Iyota, Masatoshi

Interdisciplinary Graduate School of Engineering Sciences, Kyushu University

Ikeura, Shogo

Interdisciplinary Graduate School of Engineering Sciences, Kyushu University

Wang, Dong

Art, Science and Technology Center for Cooperative Research, Kyushu University

他

http://hdl. handle. net/2324/25510

出版情報：Solid-State Electronics. 60 (1)，pp.128-133，2011-06. Elsevier バージョン：

権利関係: (C) 2011 Elsevier Ltd. 


\title{
Effective passivation of defects in Ge-rich SiGe-on-insulator substrates by $\mathrm{Al}_{2} \mathrm{O}_{3}$ deposition and subsequent post-annealing
}

\author{
Haigui Yang ${ }^{a}$, Masatoshi lyota ${ }^{\mathrm{b}}$, Shogo Ikeura $^{\mathrm{b}}$, Dong Wang ${ }^{\mathrm{a}}$, Hiroshi \\ Nakashima $^{\mathrm{a}}$ * \\ ${ }^{\mathrm{a}}$ Art, Science and Technology Center for Cooperative Research, Kyushu University \\ 6-1 Kasuga-koen, Kasuga, Fukuoka 816-8580, Japan \\ ${ }^{\mathrm{b}}$ Interdisciplinary Graduate School of Engineering Sciences, Kyushu University, \\ 6-1 Kasuga-koen, Kasuga, Fukuoka 816-8580, Japan
}

\begin{abstract}
A method of $\mathrm{Al}_{2} \mathrm{O}_{3}$ deposition and subsequent post-deposition annealing $\left(\mathrm{Al}_{2} \mathrm{O}_{3}-\mathrm{PDA}\right)$ was proposed to passivate electrically active defects in Ge-rich SiGe-on-insulator (SGOI) substrates, which were fabricated using Ge condensation by dry oxidation. The effect of $\mathrm{Al}_{2} \mathrm{O}_{3}-\mathrm{PDA}$ on defect passivation was clarified by surface analysis and electrical evaluation. It was found that $\mathrm{Al}_{2} \mathrm{O}_{3}$-PDA could not only suppress the surface reaction during Al-PDA in our previous work [Yang et al., Thin Solid Films 2010; 518: 2342], but could also effectively passivate p-type defects generated during Ge condensation. The concentration in the range of $10^{16}-10^{18} \mathrm{~cm}^{-3}$ for defect-induced acceptors and holes in Ge-rich SGOI drastically decreased after $\mathrm{Al}_{2} \mathrm{O}_{3}$-PDA. As a result of defect passivation, the electrical characteristics of both back-gate p-channel and n-channel metal-oxide-semiconductor field-effect transistors fabricated on Ge-rich SGOI were greatly improved after $\mathrm{Al}_{2} \mathrm{O}_{3}$-PDA.
\end{abstract}

Keywords: SiGe-on-insulator, $\mathrm{Ge}$ condensation, $\mathrm{Al}_{2} \mathrm{O}_{3}$-PDA, Defect passivation, Hole concentration, Acceptor concentration, MOSFET.

\footnotetext{
* Corresponding author. Tel.: +8192583 7872; fax: +81925738729.

E-mail address: nakasima@astec.kyushu-u.ac.jp (H. Nakashima).
} 


\section{Introduction}

Since the scaling of conventional Si devices has confronted many physical problems and limitations, new device technologies such as gate stack engineering, source/drain (S/D) engineering, and mobility-enhanced channel engineering are emerging to overcome scaling issues and further boost the performance of complementary metal-oxide-semiconductor (CMOS) integrated circuits [1]. Especially, mobility enhancement is becoming more important because of the saturation trend of on-current in conventional Si channel. To realize mobility enhancement, one of the most convenient method is using high-mobility Ge-based materials and III-V alloys [2]. In particular, more attention is paid to Ge-rich SiGe-on-insulator (SGOI) or Ge-on-insulator (GOI) substrates because they combine the benefits of high hole mobility from Ge and low parasitic capacitance and leak current from the "on-insulator" structure. High Ge fraction (Ge\%) of SGOI is of benefit to improve hole mobility in SGOI. Thus, it is important to fabricate a high quality SGOI substrate with high $\mathrm{Ge} \%$ and low defect density.

Tezuka et al. have proposed a convenient method of Ge condensation by dry oxidation of SiGe layer on Si-on-insulator (SOI) substrate to fabricate Ge-rich SGOI or even GOI [3]. This method has shown its advantage that SGOI with a wide range of $\mathrm{Ge} \%$ and a strain-adjusted SiGe layer could be fabricated. As a result, hole-mobility enhancement factor of approximately 10 has been successfully demonstrated in the condensed SGOI [4]. However, it is noticeable that structural defects such as stacking faults and microtwins were unintentionally induced in Ge-rich SGOI due to strain relaxation during high-temperature oxidation [5-7], and defect-free SGOI with $\mathrm{Ge} \%$ higher than $82 \%$ can not be obtained regardless of the initial parameters [7]. Furthermore, these electrically active defects act as acceptors, which cause a hole concentration $\left(N_{p}\right)$ and acceptor concentration $\left(N_{A}\right)$ as high as $10^{16}-10^{18} \mathrm{~cm}^{-3}$ in Ge-rich SGOI [8,9]. As a result, a p-channel metal-oxide-semiconductor field-effect transistor (MOSFET) on Ge-rich SGOI exhibits a large off current $\left(I_{o f f}\right)$ and is difficult to operate in full depletion (FD) mode $[5,10]$. nMOSFET on Ge-rich 
SGOI exhibits a high threshold voltage $\left(V_{T}\right)$ [8]. Efforts thus far with post-gas annealing, such as with $\mathrm{H}_{2}$ and $\mathrm{N}_{2}$, as well as optimization of the Ge condensation process, have had limited effects on passivation for these defects $[6,10,11]$. Therefore, it is still a big challenge to passivate these defects and improve the electrical properties of Ge-rich SGOI.

Recently, our group developed a method of Al deposition and subsequent post-deposition annealing (Al-PDA) [11]. With this method, Al diffused in the SiGe layer effectively passivated the electrically active defects and consequently reduced the $V_{T}$ of SGOI nMOSFET. In this case, secondary ion mass spectrometry (SIMS) revealed that Al was present in the SiGe layer at concentration of approximately $10^{18} \mathrm{~cm}^{-3}$ after Al-PDA. However, a reaction layer due to the solid-state reaction between $\mathrm{Al}$ and SiGe was unintentionally formed on the SiGe surface. This could make it difficult to perform gate stack fabrication on SGOI.

In this work, we propose the use of an $\mathrm{Al}_{2} \mathrm{O}_{3}$ insulating film instead of an $\mathrm{Al}$ film. By using $\mathrm{Al}_{2} \mathrm{O}_{3}$ deposition and subsequent post-deposition annealing $\left(\mathrm{Al}_{2} \mathrm{O}_{3}-\mathrm{PDA}\right)$ method, we sought to suppress surface reaction-layer formation, passivate p-type defects, and improve the electrical properties of Ge-rich SGOI.

\section{Experimental}

To fabricate SGOI with a wide range of Ge\% using Ge condensation by dry oxidation, two kinds of initial samples were used. The initial sample of $10 \mathrm{~nm} \mathrm{Si} / 74 \mathrm{~nm} \mathrm{Si}_{0.85} \mathrm{Ge}_{0.15} / 140 \mathrm{~nm}$ buried oxide $(\mathrm{BOX}) / \mathrm{Si}$ substrate was used to fabricate SGOI's with $\mathrm{Ge} \% \leq 50 \%$, and $10 \mathrm{~nm} \mathrm{Si} / 80$ $\mathrm{nm} \mathrm{Si}_{0.78} \mathrm{Ge}_{0.22} / 140 \mathrm{~nm} \mathrm{BOX} / \mathrm{Si}$ substrate was used to fabricate SGOI's with $\mathrm{Ge} \%>50 \%$. Considering the melting point of SiGe, we carried out Ge condensation in a $100 \% \mathrm{O}_{2}$ atmosphere at temperatures from 1200 to $1075{ }^{0} \mathrm{C}$ for $\mathrm{Ge} \% \leq 50 \%$, from 1075 to $950{ }^{0} \mathrm{C}$ for $50 \%<\mathrm{Ge} \% \leq 75 \%$, and from 950 to $900{ }^{0} \mathrm{C}$ for $\mathrm{Ge} \%>75 \%$. To evaluate the electrical properties, we fabricated back-gate pMOSFET and nMOSFET structures on SGOI. Detailed fabrication processes were shown in Fig. 1. In the case of pMOSFET fabrication in Fig. 1a, after thermally grown $\mathrm{SiO}_{2}$ was 
removed, 20-nm-thick $\mathrm{Al}_{2} \mathrm{O}_{3}$ films were first deposited on SGOI by radio frequency (RF) magnetron sputtering using an $\mathrm{Al}_{2} \mathrm{O}_{3}$ target at an Ar flow rate of $30 \mathrm{sccm}$ and an $\mathrm{RF}$ power of 60 W. The deposition rate was approximately $3 \mathrm{~nm} / \mathrm{min}$, which was measured by spectroscopic ellipsometry (SE) and transmission electron microscopy (TEM). PDA was then performed at temperatures of $500-800{ }^{0} \mathrm{C}$ for $30 \mathrm{~min}$ in $\mathrm{N}_{2}$. After PDA, $\mathrm{Al}_{2} \mathrm{O}_{3}$ films were removed by buffered-HF solutions. Then Al films were deposited and patterned as S/D electrodes. After that, mesa etching and subsequent ohmic contact annealing were done. Finally an In-Ga alloy was rubbed onto back Si to form an ohmic contact. Compared with pMOSFET fabrication, the main difference of nMOSFET fabrication, as shown in Fig. 1b, is that $n^{+} S / D$ was first formed by solid-state diffusion (SSD) of phosphorus at temperatures of $900-1000{ }^{0} \mathrm{C}$ before $\mathrm{Al}_{2} \mathrm{O}_{3}-\mathrm{PDA}$. The channel width/length of both pMOSFET and nMOSFET is $40 / 400 \mu \mathrm{m}$. Moreover, the structure and surface analysises were performed by using TEM, x-ray photoelectron spectroscopy (XPS) and optical microscope.

\section{Results and discussion}

\subsection{The structure and surface analysis}

Figure 2 shows cross-sectional image of SGOI with $\mathrm{Ge} \%=45 \%$ after $\mathrm{Al}_{2} \mathrm{O}_{3}-\mathrm{PDA}$ at $700{ }^{0} \mathrm{C}$. The $\mathrm{Al}_{2} \mathrm{O}_{3}$ layer and a flat interface at $\mathrm{Al}_{2} \mathrm{O}_{3} / \mathrm{SiGe}$ were clearly observed. The thickness of $\mathrm{Al}_{2} \mathrm{O}_{3}$ measured by TEM is approximately $20 \mathrm{~nm}$, which is the same as the measured by SE.

Figure 3 shows surface images of SGOI with $\mathrm{Ge} \%=45 \%$ before and after $\mathrm{Al}_{2} \mathrm{O}_{3}$-PDA at 700 ${ }^{0} \mathrm{C}$, which were taken with an optical microscope. As a comparison, the surface image after Al-PDA at $400{ }^{0} \mathrm{C}$ is also shown. It is noted in Fig. 3 that both top $\mathrm{Al}$ and $\mathrm{Al}_{2} \mathrm{O}_{3}$ on the surface were removed after PDA. As clearly shown in Fig. 3b, a reaction layer due to the solid-state reaction between $\mathrm{Al}$ and $\mathrm{SiGe}$ was formed on the surface after Al-PDA. Similar phenomena were also observed for Al-PDA-treated SGOI with other Ge\%. Moreover, we found that these spot-like 
patterns on the surface became larger with increasing $\mathrm{Ge} \%$. This indicates that the reaction is enhanced as $\mathrm{Ge} \%$ increases. In contrast to the results with Al-PDA, no change in the surface morphology was observed after $\mathrm{Al}_{2} \mathrm{O}_{3}$-PDA based on a comparison of Fig. $3 \mathrm{a}$ and $3 \mathrm{c}$. These results indicate that $\mathrm{Al}_{2} \mathrm{O}_{3}$, as an insulator, does not react with the SiGe layer even during high-temperature annealing, and therefore can effectively suppress the formation of a reaction-layer on the SGOI surface.

To further clarify the surface morphology, we carried out XPS measurements using an Al $K \alpha$ line. Figure 4 shows the Al 2p spectra from the surface of four kinds of samples. After Al-PDA and subsequent top-Al removal, Al $2 \mathrm{p}$ peak at $74.2 \mathrm{eV}$ was still detected, and it shifted to higher binding energy $(\mathrm{BE})$ from the position $(72.5 \mathrm{eV})$ of metal Al. This suggests that the solid-state reaction between $\mathrm{Al}$ and $\mathrm{SiGe}$ occurred during Al-PDA and caused the formation of surface-reaction layer. After $\mathrm{Al}_{2} \mathrm{O}_{3}$ deposition, the $2 \mathrm{p}$ peak at $74.9 \mathrm{eV}$ from $\mathrm{Al}$ oxidation state was clear. However, no signal from $\mathrm{Al} 2 \mathrm{p}$ was detected after $\mathrm{Al}_{2} \mathrm{O}_{3}-\mathrm{PDA}$ and subsequent top- $\mathrm{Al}_{2} \mathrm{O}_{3}$ removal. It indicates that the solid-state reaction between $\mathrm{Al}$ and $\mathrm{SiGe}$ on the surface was completely suppressed by using $\mathrm{Al}_{2} \mathrm{O}_{3}$-PDA. These XPS results are well consistent with the observation in Fig. 3.

\subsection{The effect of $\mathrm{Al}_{2} \mathrm{O}_{3}$-PDA on the reduction of $N_{p}$ in Ge-rich SGOI}

To clarify the effect of $\mathrm{Al}_{2} \mathrm{O}_{3}$-PDA on defect passivation, we first evaluated $N_{p}$ by the Hall effect measurement. Figure 5 shows the dependence of $N_{p}$ on $\mathrm{Ge} \%$ for SGOI's with and without $\mathrm{Al}_{2} \mathrm{O}_{3}$-PDA treatment. $\mathrm{Al}_{2} \mathrm{O}_{3}$-PDA was performed at an optimal annealing temperature of $700{ }^{0} \mathrm{C}$ for $\mathrm{Ge} \%<50 \%, 600{ }^{0} \mathrm{C}$ for $50 \%<\mathrm{Ge} \%<75 \%$, and $500{ }^{0} \mathrm{C}$ for $\mathrm{Ge} \%>75 \%$. The optimal conditions were determined by the drain current $\left(I_{D}\right)$ versus back-gate voltage $\left(V_{G}\right)$ characteristics of MOSFET's, which will be shown in the following sections. Clearly, defect-induced $N_{p}$ drastically increases from $10^{16}$ to $10^{18} \mathrm{~cm}^{-3}$ with an increase in $\mathrm{Ge} \%$ for SGOI's without $\mathrm{Al}_{2} \mathrm{O}_{3}$-PDA. For $\mathrm{Ge} \%<50 \%, \mathrm{Al}_{2} \mathrm{O}_{3}-\mathrm{PDA}$ reduces $N_{p}$ to a value lower than approximately $1 \times 10^{16} \mathrm{~cm}^{-3}$ (the detection 
limit of the Hall effect system for a very thin sample). When $\mathrm{Ge} \%>50 \%$, a drastic decrease in $N_{p}$ of approximately one order of magnitude was obtained after $\mathrm{Al}_{2} \mathrm{O}_{3}-\mathrm{PDA}$. While $N_{p}$ is as high as $5.0 \times 10^{18} \mathrm{~cm}^{-3}$ for as-fabricated SGOI with $\mathrm{Ge} \%=90 \%$, it decreased to $5.5 \times 10^{17} \mathrm{~cm}^{-3}$ after $\mathrm{Al}_{2} \mathrm{O}_{3}$-PDA. Thus, $\mathrm{Al}_{2} \mathrm{O}_{3}$-PDA is a very effective method for the passivation of electrically active p-type defects in Ge-rich SGOI. The measured resistivity was correspondingly increased by approximately one order of magnitude after $\mathrm{Al}_{2} \mathrm{O}_{3}$-PDA treatment.

\subsection{The effect of $\mathrm{Al}_{2} \mathrm{O}_{3}$-PDA on the electrical properties of SGOI pMOSFET}

The effect of $\mathrm{Al}_{2} \mathrm{O}_{3}$-PDA on the electrical properties of SGOI pMOSFET was evaluated by using the structure in Fig. 1a. The $I_{D^{-}} V_{G}$ characteristics for SGOI's with Ge\% $\%=25,45,65$ and $90 \%$ are shown in Fig. 6, from which the flatband voltage $\left(V_{F B}\right)$, on/off current $\left(I_{\text {on/off }}\right)$ ratio, and FD voltage $\left(V_{F D}\right)$ were extracted, and are summarized in Table 1. $I_{o n}$ and $I_{\text {off }}$ are defined as the on-state drain current and off-state leakage current of pMOSFET, respectively. $V_{F D}$ is defined as the gate-bias voltage at $I_{o f f}$. Table 1 indicates that, while there is almost no difference in $V_{F B}$, there are significant differences in both the $I_{\text {on/off }}$ ratio and $V_{F D}$ between Ge-rich SGOI's with and without $\mathrm{Al}_{2} \mathrm{O}_{3}-\mathrm{PDA}$.

When $\mathrm{Ge} \%=25 \%$, since $N_{p}$ is lower than $1 \times 10^{16} \mathrm{~cm}^{-3}$ regardless of whether $\mathrm{Al}_{2} \mathrm{O}_{3}-\mathrm{PDA}$ is treated or not (See Fig. 5), both pMOSFET's with and without $\mathrm{Al}_{2} \mathrm{O}_{3}-\mathrm{PDA}$ exhibit a well-behaved $I_{D^{-}} V_{G}$ with a high $I_{o n / o f f}$ ratio and a low $V_{F D}$. However, with an increase in $\mathrm{Ge} \%, I_{\text {off }}$ drastically increases for as-fabricated SGOI's. This phenomena have been observed by other group and our

previous work $[5,10]$. When $\mathrm{Ge} \%$ increases to $90 \%$, the $I_{\text {on/off }}$ ratio decreases to less than $10^{4}$. We think that a high $N_{p}$ shown in Fig. 5 is one of the main causes of the low $I_{\text {on/off }}$ ratio besides the impact of band gap narrowing. Another disadvantage induced by a high $N_{p}$ is the increasing in $V_{F D}$. Therefore, the pMOSFET becomes more difficult to operate in FD mode with an increase in Ge\%.

Based on a comparison of Ge-rich SGOI's with and without $\mathrm{Al}_{2} \mathrm{O}_{3}-\mathrm{PDA}$ (Figs. 6b-6d), we found that $\mathrm{Al}_{2} \mathrm{O}_{3}$-PDA began to become effective when $\mathrm{Ge} \% \geq 45 \%$. With increasing $\mathrm{Ge} \%$, it 
greatly improved the electrical properties of SGOI pMOSFET's with Ge $\%=65$ and $90 \%$. One improvement is that the $I_{\text {off }}$ decreases by more than one order of magnitude and consequently the $I_{\text {on/off }}$ ratio is increased to approximately $10^{5}$, as shown in Table 1 . Another is that pMOSFET can be easily operated in FD mode with a low $V_{F D}$ after $\mathrm{Al}_{2} \mathrm{O}_{3}$-PDA treatment. These improvements in electrical properties with $\mathrm{Al}_{2} \mathrm{O}_{3}$-PDA are consistent with the reduction in $N_{p}$ shown in Fig. 5 .

We also studied the effect of $\mathrm{Al}_{2} \mathrm{O}_{3}$-PDA on carrier transport properties. Figure 7 shows the bottom-channel hole mobility for SGOI's with and without $\mathrm{Al}_{2} \mathrm{O}_{3}-\mathrm{PDA}$, which were obtained by using the $I_{D^{-}} V_{G}$ characteristics of pMOSFET [5]. Although $\mathrm{Al}_{2} \mathrm{O}_{3}$-PDA can effectively improve the $I_{\text {on/off }}$ ratio by decreasing $I_{\text {off }}$, Fig. 7 shows that it has limited impact on the enhancement of extracted hole mobility. In the case of SGOI with $\mathrm{Ge} \%=90 \%$, a decrease in mobility was observed, although a high mobility value of around $400 \mathrm{~cm}^{2} / \mathrm{V}^{\circ} \mathrm{s}$ was expected. This may be attributed to the influence of a top surface without passivation because the SiGe layer is less than $20 \mathrm{~nm}$ thick $[5,12]$.

\subsection{The effect of $\mathrm{Al}_{2} \mathrm{O}_{3}-\mathrm{PDA}$ on the electrical properties of SGOI nMOSFET}

The effect of $\mathrm{Al}_{2} \mathrm{O}_{3}$-PDA on the electrical properties of SGOI nMOSFET was also studied by using the structure in Fig. 1 b. Figure 8 shows the $I_{D^{-}} V_{G}$ characteristics for SGOI's with $\mathrm{Ge} \%=25$, 45, and 65\%, from which the $V_{T}$ and subthreshold swing $(S)$ were determined, and are summarized in Table 2. Since the SiGe layer in S/D region will be evaporated during $\mathrm{n}^{+} \mathrm{S} / \mathrm{D}$ fabrication using SSD at high temperature annealing when $\mathrm{Ge} \%$ increases to $90 \%$, we can not obtain the results of SGOI nMOSFET with $\mathrm{Ge} \%=90 \%$.

Obviously different from pMOSFETs, as-fabricated SGOI nMOSFETs exhibit a poor behavior with a high $V_{T}$ even though $\mathrm{Ge} \%$ is low. The detailed study for this phenomena was done in our previous work [8]. According to this study, we have found $N_{A}$ was much higher than $N_{p}$ for low-Ge\% SGOI due to the existence of deep acceptor level, which caused high $V_{T}$ for low-Ge\% SGOI. With an increase in $\mathrm{Ge} \%, V_{T}$ drastically increases. By a comparison of SGOI's with and 
without $\mathrm{Al}_{2} \mathrm{O}_{3}-\mathrm{PDA}$, we found that $\mathrm{Al}_{2} \mathrm{O}_{3}$-PDA treatment greatly improved nMOSFET characteristics. The $V_{T}$ 's for all SGOI's were significantly reduced after $\mathrm{Al}_{2} \mathrm{O}_{3}-\mathrm{PDA}$. Here it is noted that the change of $I_{\mathrm{D}}-V_{\mathrm{G}}$ characteristics for nMOSFETs due to the $\mathrm{Al}_{2} \mathrm{O}_{3}-\mathrm{PDA}$ is obviously different from that for pMOSFETs in Fig. 6. This is because SGOI nMOSFETs operate under inversion mode while pMOSFETs operate under accumulation mode.

The interface-state density $\left(D_{i t}\right)$ of $\mathrm{SiGe} / \mathrm{BOX}$ and $N_{A}$ were extracted from the obtained values of $V_{T}$ and $S$ in Table 2, and the results are shown in Figs. 9 and 10, respectively. The detailed extraction method has been described elsewhere [8,11]. Although Fig. 9 shows that $\mathrm{Al}_{2} \mathrm{O}_{3}$-PDA has limited effect on the reduction of $D_{i t}$, it is clear from Fig. 10 that $\mathrm{Al}_{2} \mathrm{O}_{3}-\mathrm{PDA}$ significantly reduced high $N_{A}$. Furthermore, it becomes more effective with an increase in PDA temperature. The decrease in $N_{A}$ by approximately two orders of magnitude was achieved for all SGOI's at the optimal temperatures. In particular when $\mathrm{Ge} \%=65 \%, N_{A}$ as high as $5 \times 10^{18} \mathrm{~cm}^{-3}$ was reduced to $9 \times 10^{16} \mathrm{~cm}^{-3}$ after $\mathrm{Al}_{2} \mathrm{O}_{3}$-PDA treatment. Therefore, the decrease in $N_{A}$ is responsible for the improved nMOSFET characteristics with low $V_{T}$.

In principle, $\mathrm{Al}_{2} \mathrm{O}_{3}$ has a thermodynamically stable structure. However, in this study $\mathrm{Al}_{2} \mathrm{O}_{3}$ films were prepared by RF magnetron sputtering using an $\mathrm{Al}_{2} \mathrm{O}_{3}$ target at an Ar flow. The structure of $\mathrm{Al}_{2} \mathrm{O}_{3}$ prepared by this method should be not perfect stable because we found that thin $\mathrm{SiO}_{2}$ films was formed somewhere on SiGe surface after $\mathrm{Al}_{2} \mathrm{O}_{3}$-PDA by TEM observation. Similar phenomena have also been reported by other group [13]. Therefore, it is possible that Al was diffused in SiGe layer during high temperature annealing of $\mathrm{Al}_{2} \mathrm{O}_{3}$. But $\mathrm{Al}$ diffusion is difficult during $\mathrm{Al}_{2} \mathrm{O}_{3}$-PDA because of its stable structure, which is reflected in the fact that $\mathrm{Al}_{2} \mathrm{O}_{3}-\mathrm{PDA}$ requires a higher temperature than $\mathrm{Al}-\mathrm{PDA}\left(400{ }^{\circ} \mathrm{C}\right)$ [11]. Compared with $\mathrm{Al}-\mathrm{PDA}, \mathrm{Al}_{2} \mathrm{O}_{3}-\mathrm{PDA}$ is somewhat less effective at reducing the $V_{T}$ and $S$ of nMOSFET, and consequently less effective at reducing $N_{A}$ and $D_{i t}$. Based on this fact, the concentration of $\mathrm{Al}$ existed in the SiGe layer after $\mathrm{Al}_{2} \mathrm{O}_{3}$-PDA should be less than $10^{18} \mathrm{~cm}^{-3}$ after Al-PDA, which was measured by SIMS method. 
The effect of $\mathrm{Al}_{2} \mathrm{O}_{3}$-PDA suggests that interstitial $\mathrm{Al}$ diffused in the $\mathrm{SiGe}$ layer exists as positive-charge state $\left(\mathrm{Al}^{+}\right)$and therefore can effectively passivate negatively charged p-type defects.

\section{Conclusion}

We have demonstrated the effect of $\mathrm{Al}_{2} \mathrm{O}_{3}$-PDA on the passivation of electrically active defects for Ge-rich SGOI fabricated using Ge condensation by dry oxidation. The surface analysis by optical microscope and XPS indicated that $\mathrm{Al}_{2} \mathrm{O}_{3}$-PDA effectively suppressed the formation of a reaction-layer on the surface. From Hall-effect measurements, it was found that $\mathrm{Al}_{2} \mathrm{O}_{3}-\mathrm{PDA}$ reduced $N_{p}$ by approximately one order of magnitude in Ge-rich SGOI's, which suggested that the electrically active p-type defects were effectively passivated. As a result of this decrease in $N_{p}$, Ge-rich SGOI pMOSFET exhibits a well-behaved characteristics with a high $I_{\text {on/off }}$ ratio and a low $V_{F D}$ after $\mathrm{Al}_{2} \mathrm{O}_{3}$-PDA. Our results also showed that $\mathrm{Al}_{2} \mathrm{O}_{3}$-PDA greatly reduced the $V_{T}$ of SGOI nMOSFET. The decrease in $N_{A}$ by approximately two orders of magnitude was achieved for all SGOI's.

\section{Acknowledgements}

This study was supported in part by STARC, JSPS, a Grant-in-Aid for Science Research on Priority Areas (20035011) and a Science Research A (21246054) from The Ministry of Education, Culture, Sports, Science and Technology of Japan.

\section{References}

[1] International Technology Roadmap for Semiconductors (ITRS). http://public.itrs.net/.

[2] Takagi S, Tezuka T, Irisawa T, Nakaharai S, Numata T, Usuda K, et al. Device structures and carrier transport properties of advanced CMOS using high mobility channels. Solid-State Electronics 2007;51:526-36. 
[3] Tezuka T, Sugiyama N, Mizuno T, Suzuki M, Takagi S. A novel fabrication technique of ultra-thin silicon germanium buffer layers for sub-100 $\mathrm{nm}$ strained silicon-on-insulator MOSFETs. Jpn J Appl Phys 2001;40:2866-74.

[4] Tezuka T, Nakaharai S, Moriyama Y, Sugiyama N, Takagi S. High-mobility strained SiGe-on-insulator pMOSFETs with Ge-rich surface channels fabricated by local condensation technique. IEEE Electron Device Lett 2005;26:243-5

[5] Yang H, Wang D, Nakashima H, Gao H, Hirayama K, Ikeda K, et al. Influence of top surface passivation on bottom-channel hole mobility of ultrathin SiGe- and Ge-on-insulator. Appl Phys Lett 2008;93:072104-1-4-3

[6] Hirashita N, Nakaharai S, Moriyama Y, Usuda K, Tezuka T, Sugiyama N et al. Planar defect formation mechanism in Ge-rich SiGe-on-insulator substrates during Ge condensation process. Thin Solid Films 2008;517:407-11.

[7] Vincent B, Damlencourt J -F, Delaye V, Gassilloud R, Clavelier L, Morand Y. Stacking fault generation during relaxation of silicon germanium on insulator layers obtained by the Ge condensation technique. Appl Phys Lett 2007;90:074101-1-1-3.

[8] Yang H, Wang D, Nakashima H. Evidence for existence of deep acceptor levels in SiGe-on-insulator substrate fabricated using Ge condensation technique. Appl Phys Lett 2009;95:122103-1-3-3.

[9] Hirashita N, Moriyama Y, Nakaharai S, Irisawa T, Sugiyama N, Takagi S. Deformation induced holes in Ge-rich SiGe-on-insulator and Ge-on-insulator substrates fabricated by $\mathrm{Ge}$ condensation process. Appl Phys Express 2008;1:101401-1-1-3.

[10] Souriau L, Nguyen T, Augendre E, Loo R, Terzieva V, Caymax M, et al. High-hole-mobility silicon germanium on insulator substrates with high crystalline quality obtained by the germanium condensation technique. J Electrochem Soc 2009;156:H208-13.

[11] Yang H, Wang D, Nakashima H, Hirayama K, Kojima S, Ikeura S. Defect control by 
Al-deposition and the subsequent post-annealing for SiGe-on-insulator substrates with different Ge fractions. Thin Solid Films 2010;518:2342-5.

[12] Hamaide G, Allibert F, Hovel H, Cristoloveanu S. Impact of free-surface passivation on silicon on insulator buried interface properties by pseudotransistor characterization. J Appl Phys 2007;101:114513-1-3-6.

[13] Di Z, Zhang M, Liu W, Shen Q, Luo S, Song Z, Lin C, Huang A, Chu P. Interfacial and electrical characteristics of $\mathrm{Al} 2 \mathrm{O} 3$ gate dielectric on fully depleted SiGe on insulator. Appl Phys Lett 2005;86:262102-1-2-3. 
Table 1. $V_{F B}, I_{o n / o f f}$ ratio, and $V_{F D}$ obtained from the $I_{D^{-}} V_{G}$ characteristics of pMOSFET with and without $\mathrm{Al}_{2} \mathrm{O}_{3}$-PDA. The PDA's were performed at temperatures of $700{ }^{0} \mathrm{C}$ for $\mathrm{Ge} \%=25$ and $45 \%$, $600{ }^{0} \mathrm{C}$ for $\mathrm{Ge} \%=65 \%$, and $500{ }^{0} \mathrm{C}$ for $\mathrm{Ge} \%=90 \%$, respectively.

\begin{tabular}{cccccccc}
\hline \multirow{2}{*}{$\mathrm{Ge} \%$} & \multicolumn{2}{c}{$V_{F B}(\mathrm{~V})$} & \multicolumn{2}{c}{$I_{\text {on/off }}$ ratio } & & \multicolumn{2}{c}{$V_{F D}(\mathrm{~V})$} \\
\cline { 6 - 8 } & $\mathrm{w} / \mathrm{o}$ & $\mathrm{w} /$ & $\mathrm{w} / \mathrm{o}$ & $\mathrm{w} /$ & $\mathrm{w} / \mathrm{o}$ & $\mathrm{w} /$ \\
\hline $25 \%$ & -4.2 & -3.9 & $7.3 \times 10^{5}$ & $7.5 \times 10^{5}$ & 4.4 & 3.8 \\
$45 \%$ & -2.6 & -3.0 & $3.1 \times 10^{5}$ & $8.1 \times 10^{5}$ & 7.8 & 5.4 \\
$65 \%$ & -4.3 & -4.3 & $5.1 \times 10^{3}$ & $9.8 \times 10^{4}$ & 21.8 & 6.4 \\
$90 \%$ & -2.2 & -2.6 & $3.3 \times 10^{3}$ & $8.6 \times 10^{4}$ & 40.2 & 14.2 \\
\hline
\end{tabular}

Table $2 V_{T}$ and $S$ obtained from $I_{D^{-}} V_{G}$ characteristics of nMOSFET with and without $\mathrm{Al}_{2} \mathrm{O}_{3}-\mathrm{PDA}$ (Units. $V_{T}: \mathrm{V} ; S: \mathrm{V} /$ decade).

\begin{tabular}{ccccccccc}
\hline \multirow{2}{*}{$\mathrm{Ge} \%$} & \multicolumn{2}{c}{$25 \%$} & & \multicolumn{2}{c}{$45 \%$} & & \multicolumn{2}{c}{$65 \%$} \\
\cline { 2 - 3 } \cline { 7 - 8 } & $V_{T}$ & $S$ & & $V_{T}$ & $S$ & & $V_{T}$ & $S$ \\
\hline w/o PDA & 29.3 & 2.5 & 40.9 & 2.5 & 75.0 & 6.7 \\
$500{ }^{\circ} \mathrm{C}$ & -- & -- & -- & -- & 21.8 & 2.6 \\
$600{ }^{\circ} \mathrm{C}$ & 14.1 & 1.8 & 16.2 & 1.7 & 13.0 & 2.2 \\
$700{ }^{\circ} \mathrm{C}$ & 8.6 & 1.2 & 11.2 & 1.6 & 14.7 & 2.7 \\
$800^{\circ} \mathrm{C}$ & 9.6 & 1.3 & 11.8 & 1.7 & -- & -- \\
\hline
\end{tabular}




\section{Figure captions}

Fig. 1. The fabrication processes of back gate (a) pMOSFET and (b) nMOSFET, and the treatment with $\mathrm{Al}_{2} \mathrm{O}_{3}$-PDA.

Fig. 2. Cross-sectional TEM image of SGOI with $\mathrm{Ge} \%=45 \%$ after $\mathrm{Al}_{2} \mathrm{O}_{3}-\mathrm{PDA}$ at $700{ }^{0} \mathrm{C}$.

Fig. 3. The surface images of SGOI with $\mathrm{Ge} \%=45 \%$ before (a) PDA, after (b) Al-PDA at $400{ }^{0} \mathrm{C}$ and (c) $\mathrm{Al}_{2} \mathrm{O}_{3}-\mathrm{PDA}$ at $700{ }^{\circ} \mathrm{C}$.

Fig. 4. XPS spectra for SGOI with $\mathrm{Ge} \%=45 \%$ after (a) $\mathrm{Al}$ deposition, (b) Al-PDA at $400{ }^{0} \mathrm{C}$ and the subsequent top- $\mathrm{Al}$ removal, (c) $\mathrm{Al}_{2} \mathrm{O}_{3}$ deposition, and (d) $\mathrm{Al}_{2} \mathrm{O}_{3}-\mathrm{PDA}$ at $700{ }^{\circ} \mathrm{C}$ and the subsequent top- $\mathrm{Al}_{2} \mathrm{O}_{3}$ removal.

Fig. 5. Dependence of $N_{p}$ on $\mathrm{Ge} \%$ with (w/) and without (w/o) $\mathrm{Al}_{2} \mathrm{O}_{3}-\mathrm{PDA}$. The PDA's were performed at an optimal annealing temperature of $700{ }^{0} \mathrm{C}$ for $\mathrm{Ge} \%<50 \%, 600{ }^{0} \mathrm{C}$ for $50 \%<\mathrm{Ge} \%<75 \%$, and $500{ }^{0} \mathrm{C}$ for $\mathrm{Ge} \%>75 \%$, respectively.

Fig. 6. $I_{D^{-}} V_{G}$ characteristics for SGOI pMOSFET of Ge\%= (a) $25 \%$, (b) $45 \%$, (c) $65 \%$ and (d) $90 \%$ with and without $\mathrm{Al}_{2} \mathrm{O}_{3}$-PDA.

Fig. 7. Dependence of bottom-channel hole mobility on $\mathrm{Ge} \%$ with and without $\mathrm{Al}_{2} \mathrm{O}_{3}-\mathrm{PDA}$. The PDA's were performed at temperatures of $700{ }^{0} \mathrm{C}$ for $\mathrm{Ge} \%=25$ and $45 \%, 600{ }^{0} \mathrm{C}$ for $\mathrm{Ge} \%=65 \%$, and $500{ }^{0} \mathrm{C}$ for $\mathrm{Ge} \%=90 \%$, respectively. The corresponding thickness of SiGe layer was also given.

Fig. 8. $I_{D^{-}} V_{G}$ characteristics for SGOI nMOSFET of Ge\%= (a) $25 \%$, (b) $45 \%$, and (c) $65 \%$ with and without $\mathrm{Al}_{2} \mathrm{O}_{3}-\mathrm{PDA}$.

Fig. 9. Dependence of $D_{i t}$ on Ge\% for SGOI's with and without $\mathrm{Al}_{2} \mathrm{O}_{3}$-PDA.

Fig. 10. Dependence of $N_{A}$ on $\mathrm{Ge} \%$ for SGOI's with and without $\mathrm{Al}_{2} \mathrm{O}_{3}-\mathrm{PDA}$. 


\section{(a) PMOSFET}
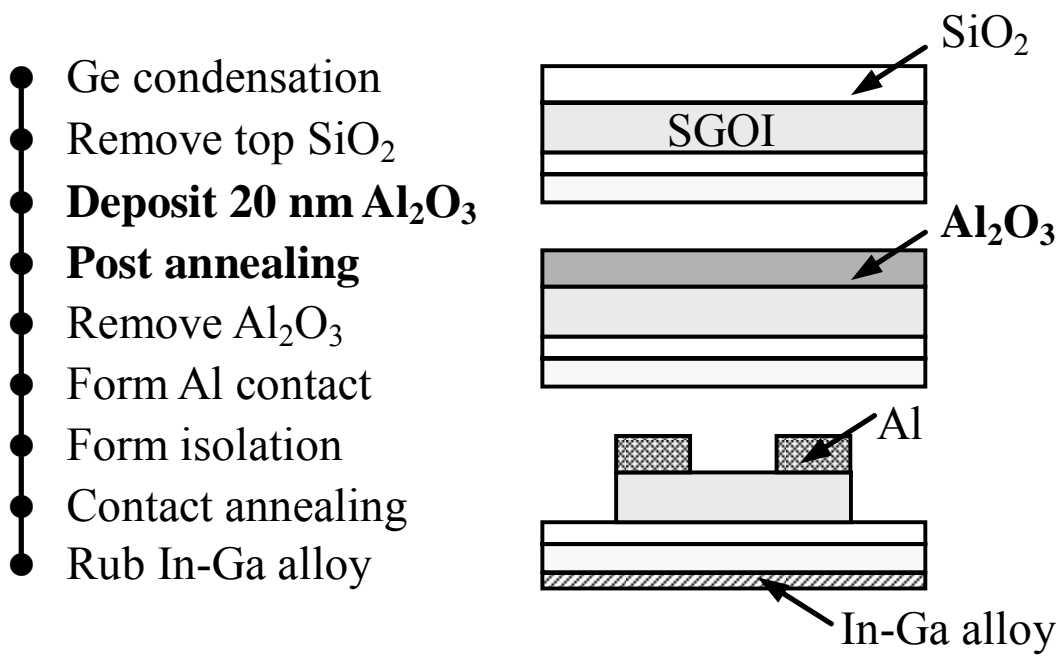

(b) nMOSFET
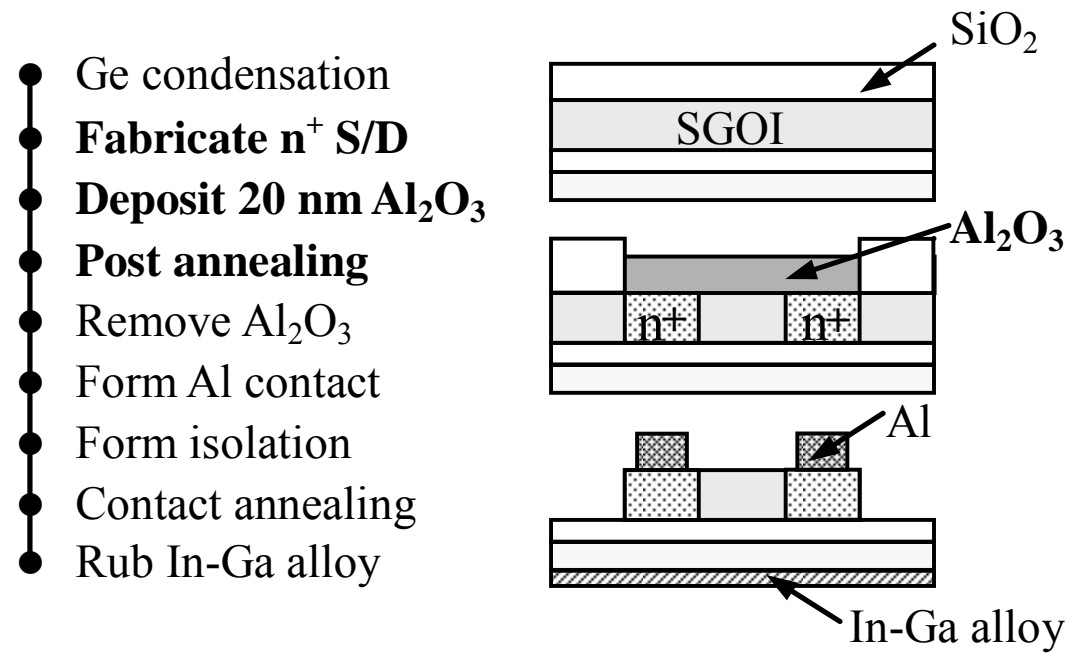

Figure 1 


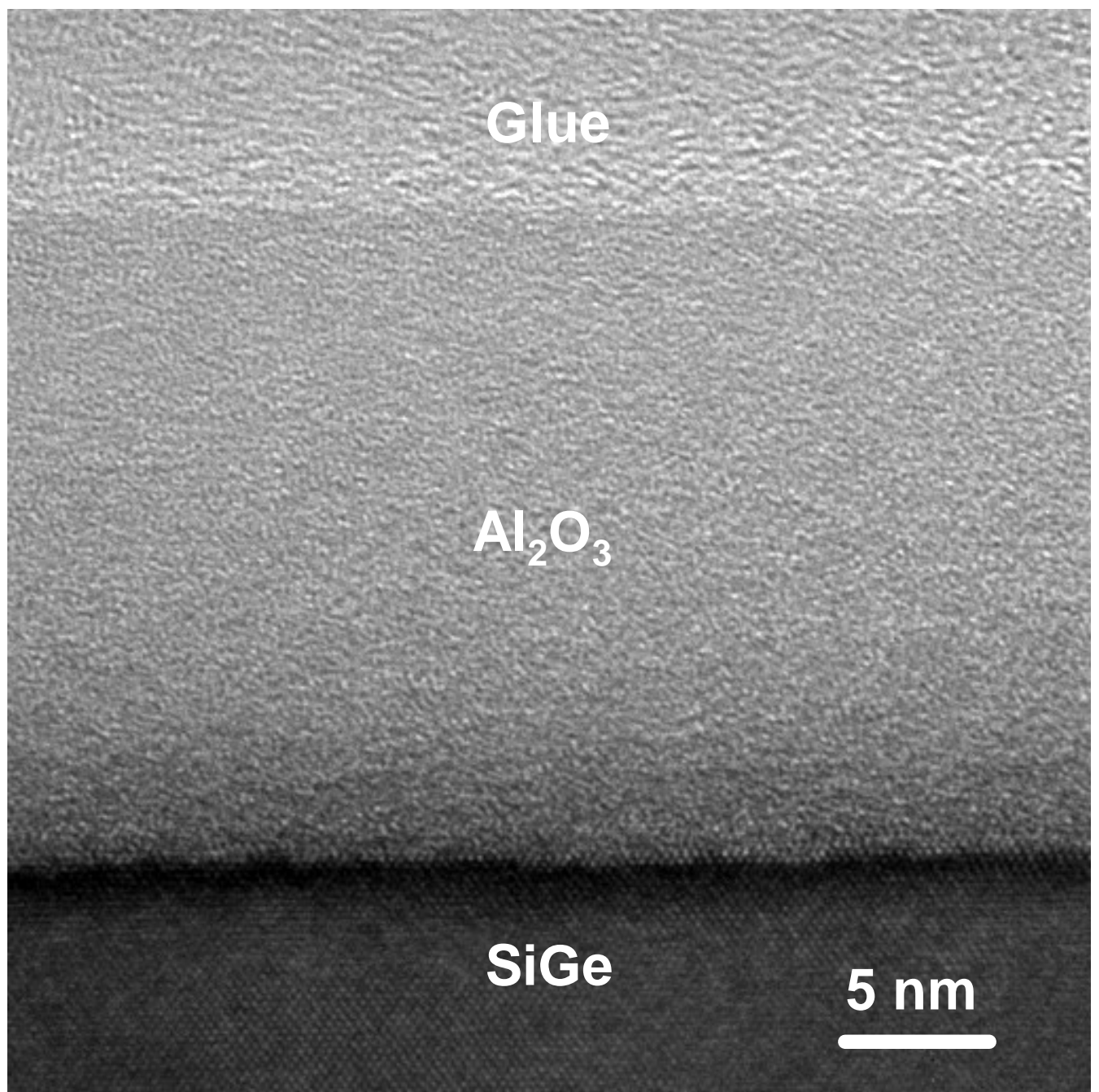

Figure 2 
(a) Before PDA
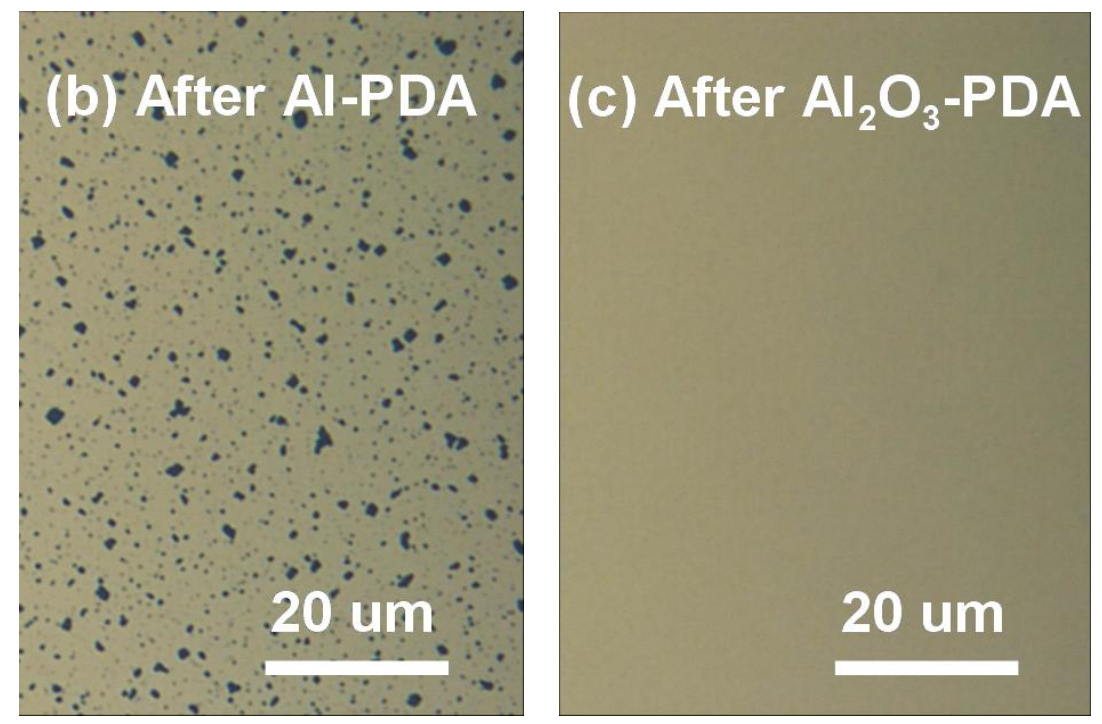

Figure 3 


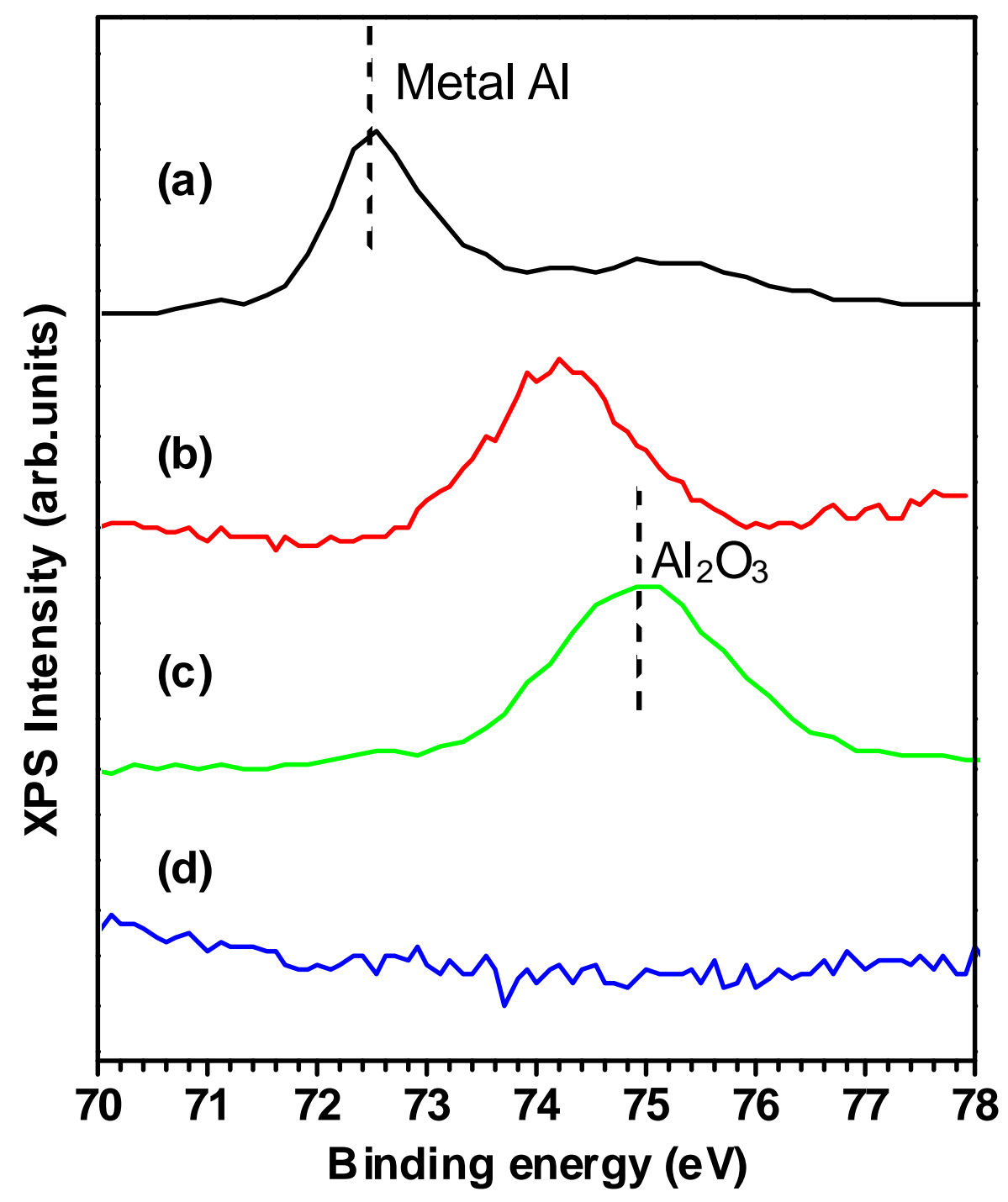

Figure 4 


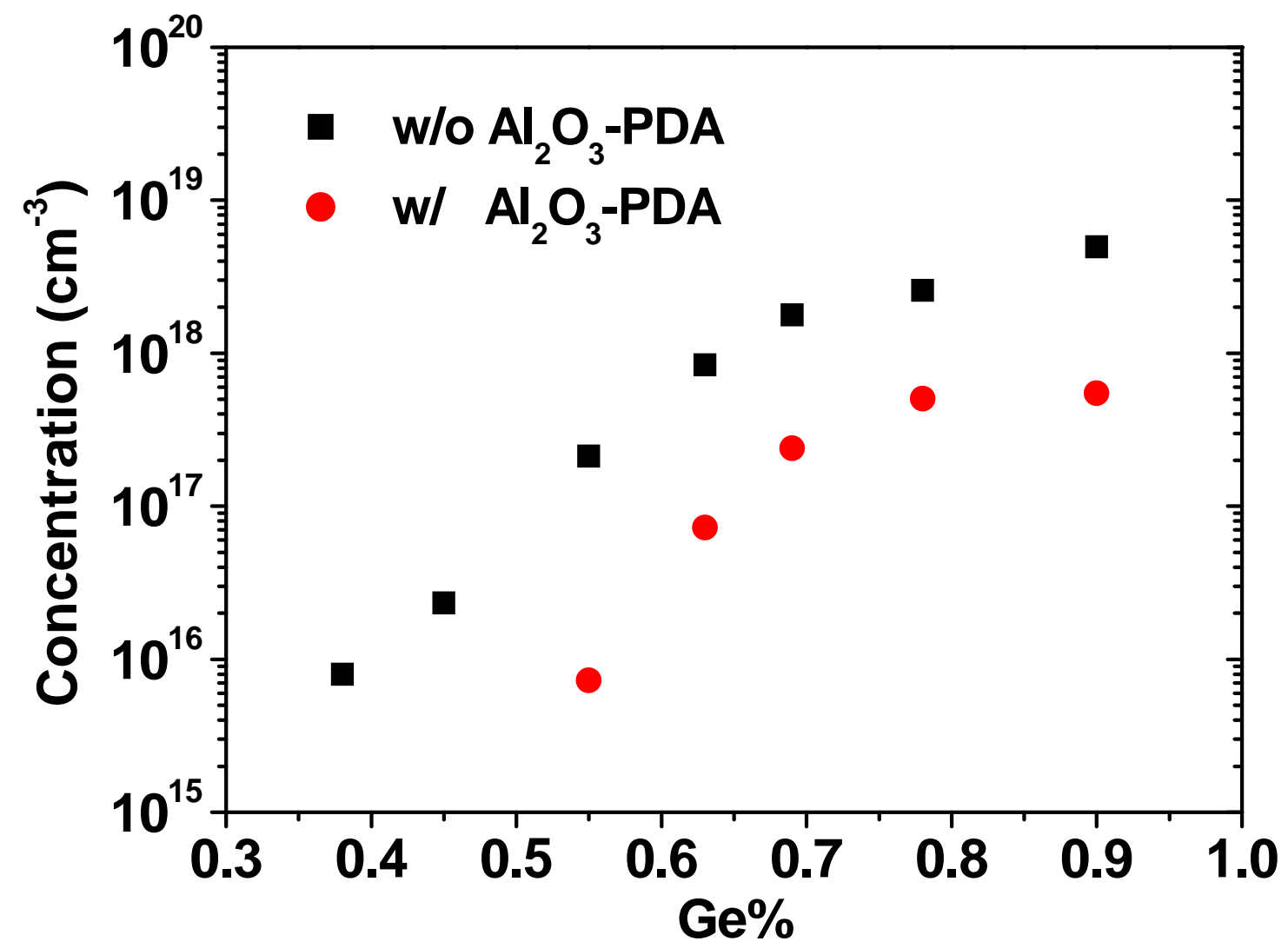

Figure 5 


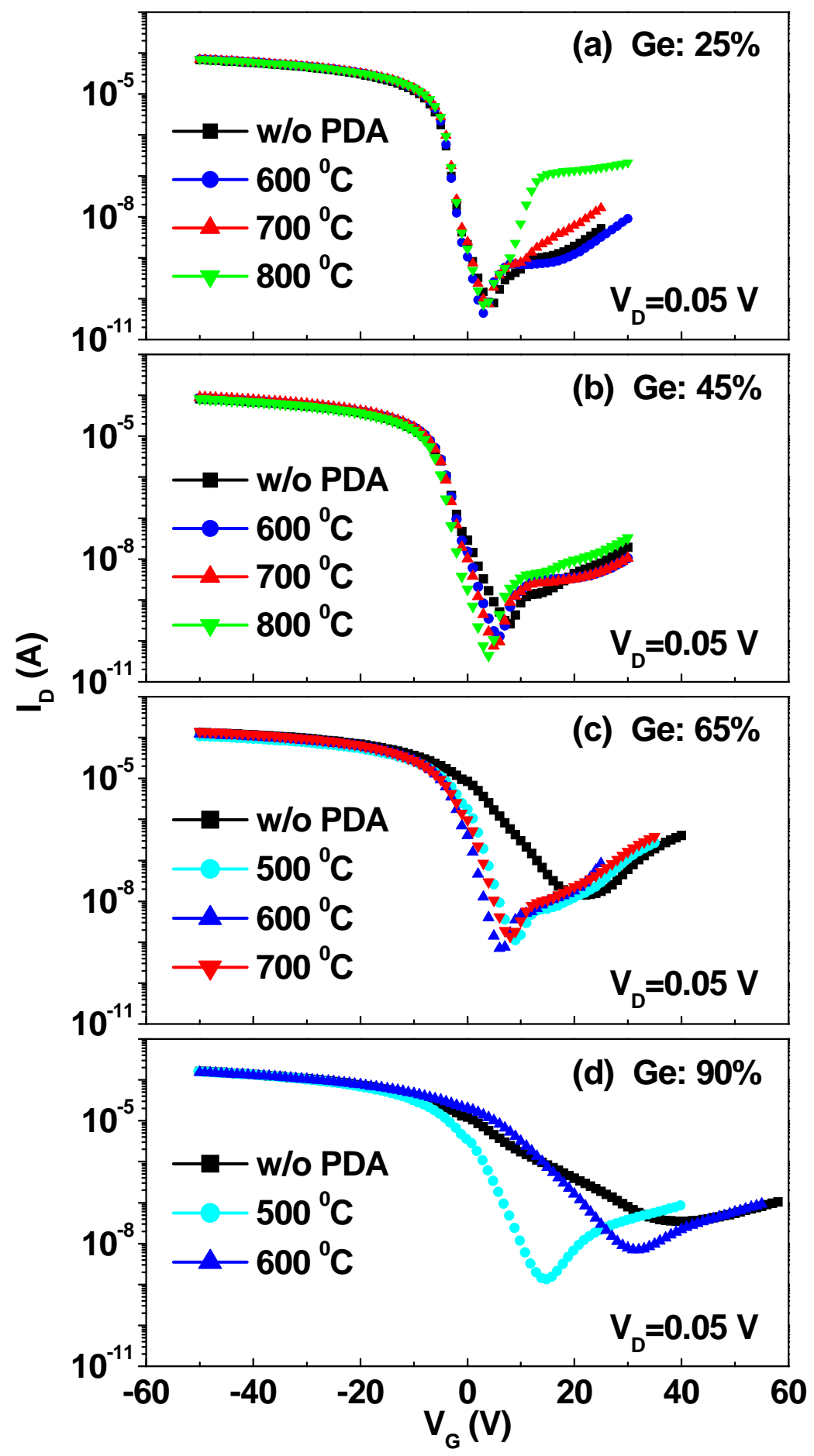

Figure 6 


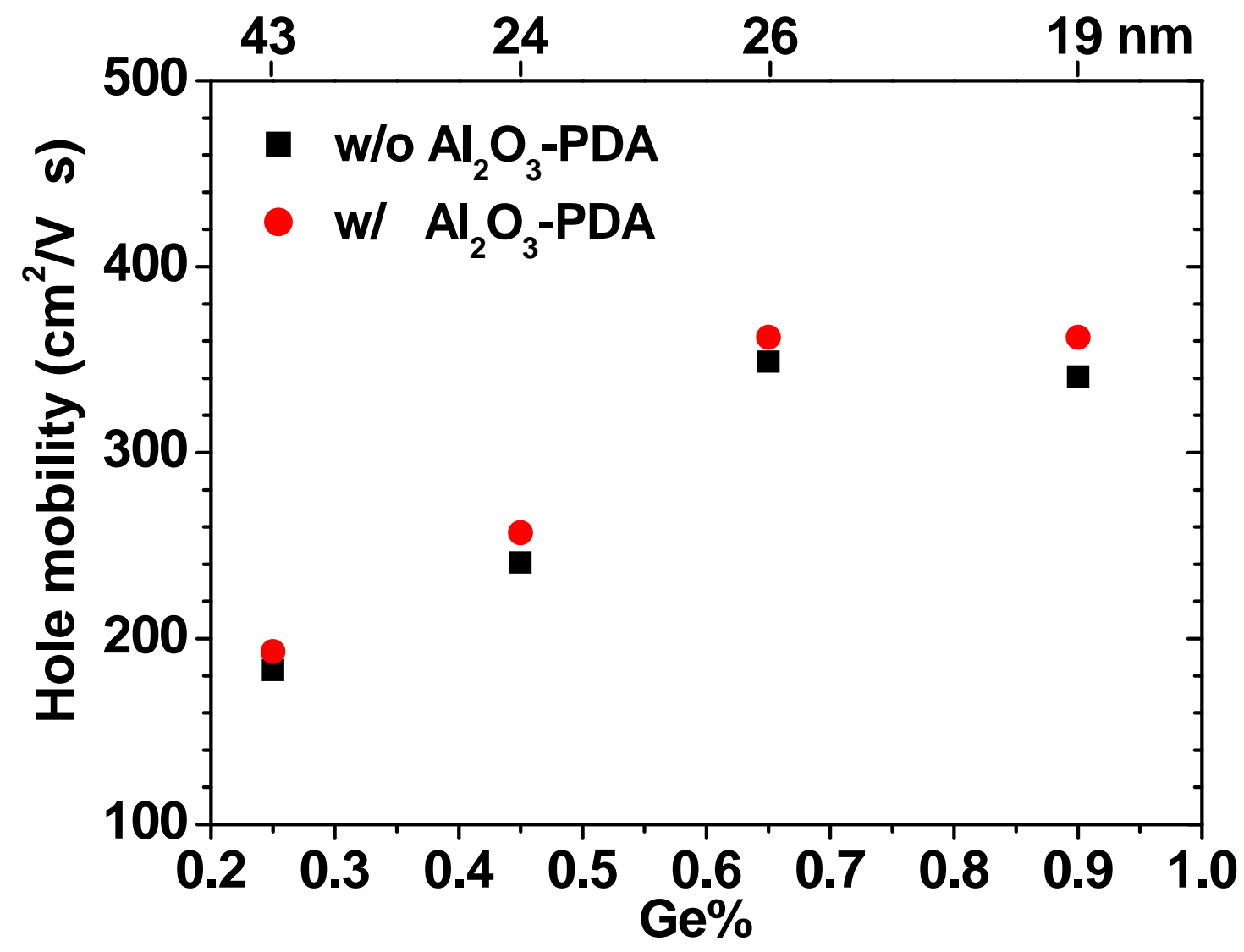

Figure 7 


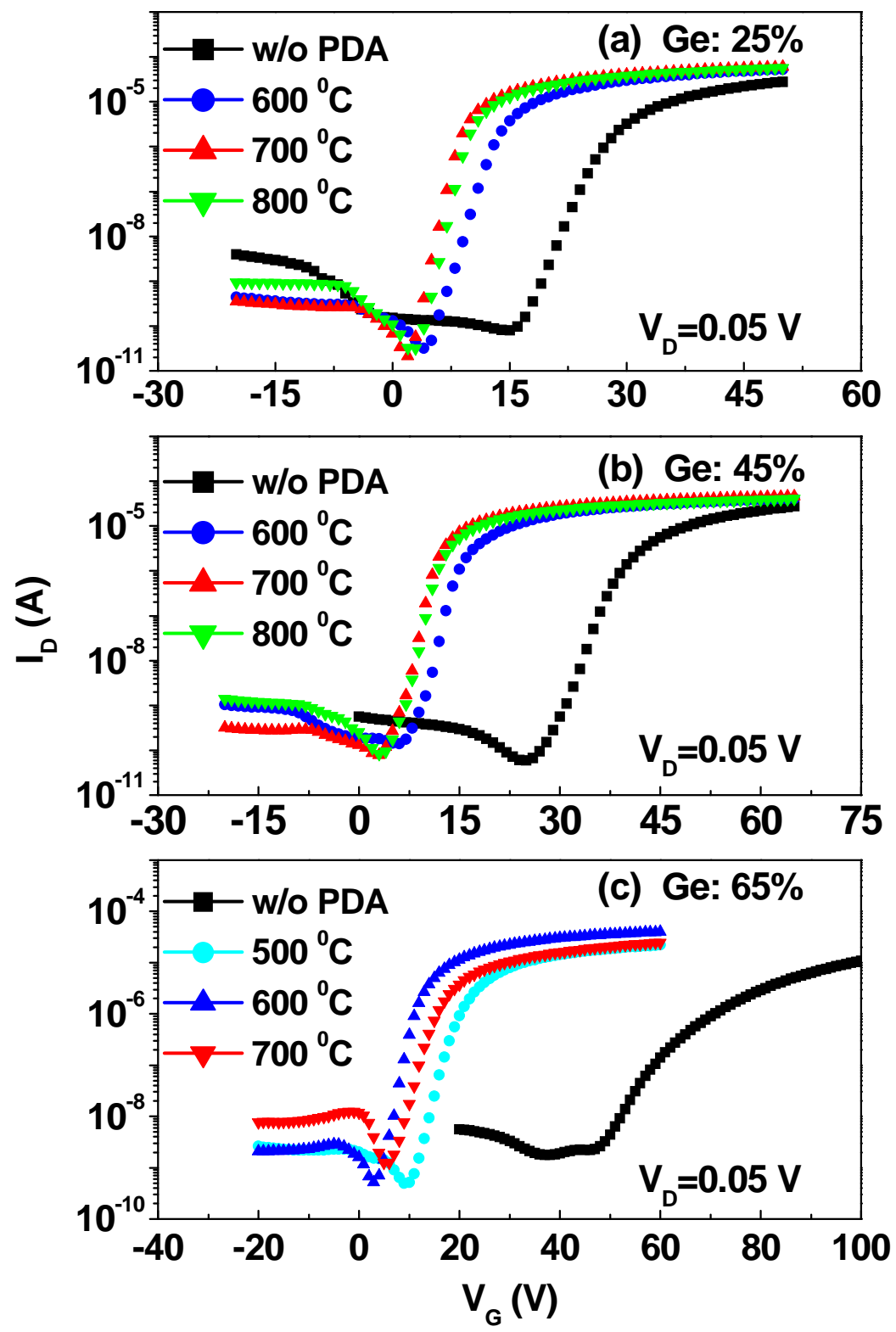

Figure 8 


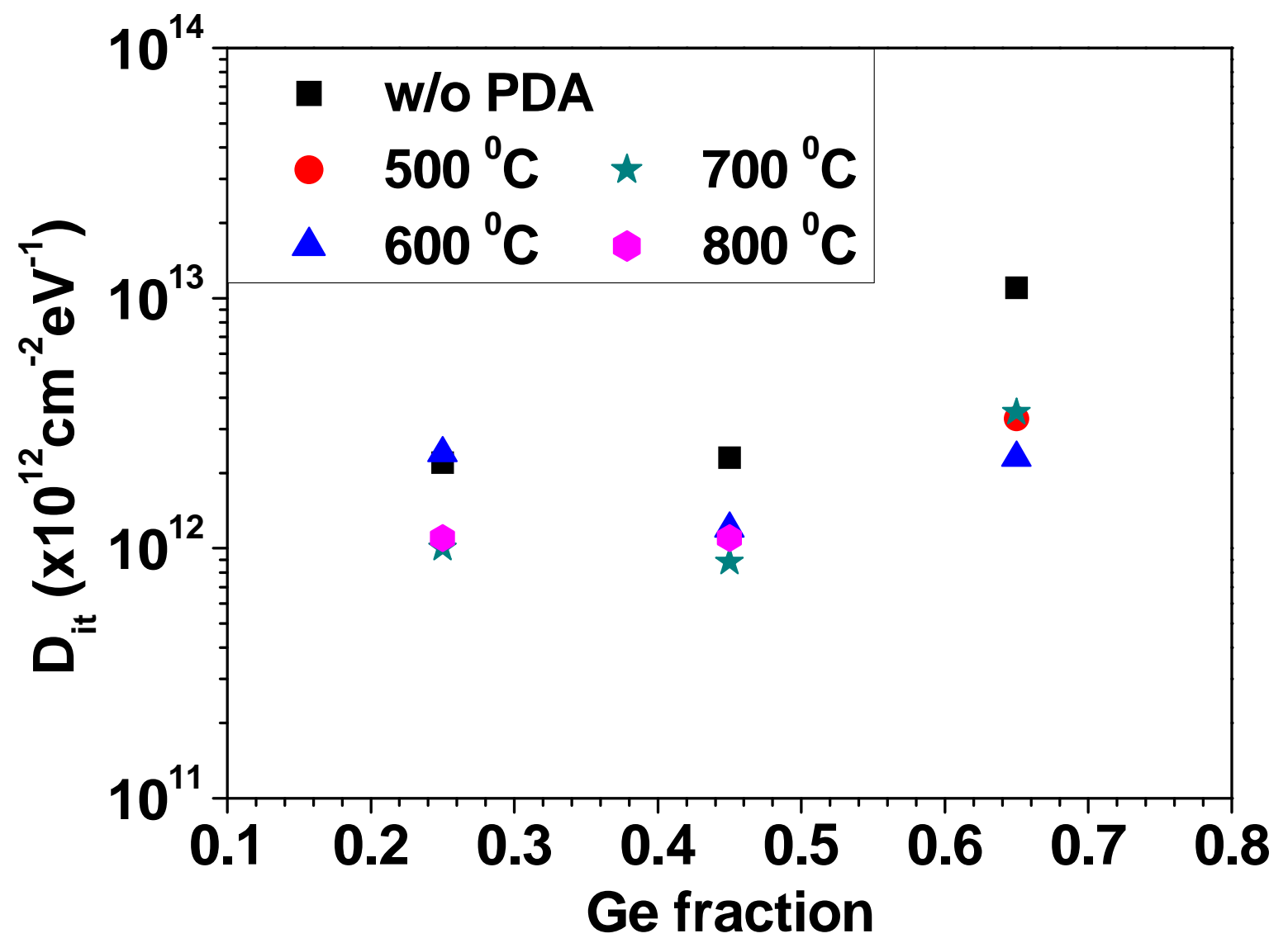

Figure 9 


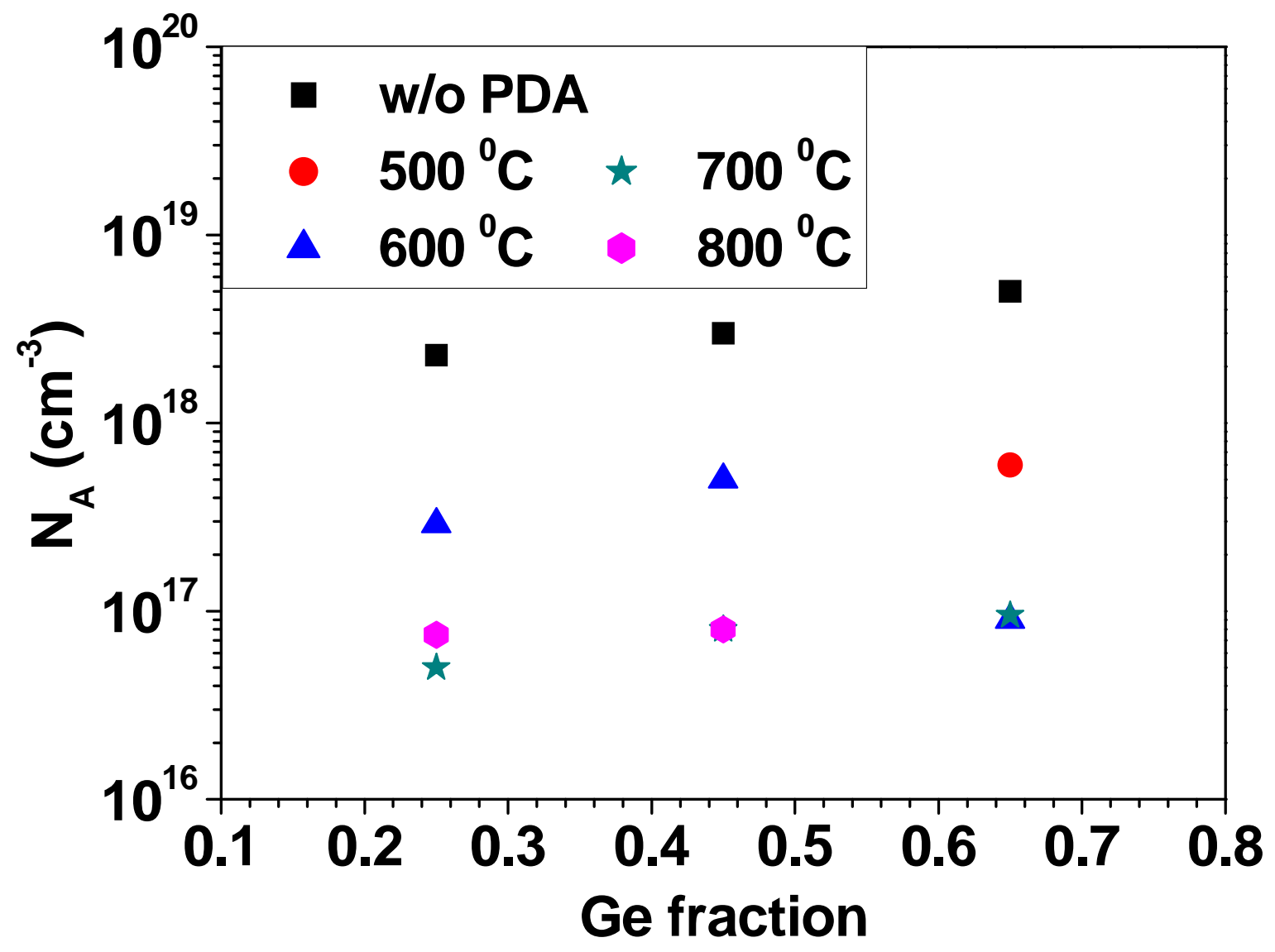

Figure 10 